\title{
ORIGINAL
}

\section{Randomised controlled trial of oxygen therapy and high-flow nasal therapy in African children with pneumonia}

\author{
K. Maitland ${ }^{1,4^{*}}$, S. Siguli ${ }^{2}$, P. Olupot-Olupot ${ }^{3}$, M. Hamaluba ${ }^{4}$, K. Thomas ${ }^{5}$, F. Alaroker ${ }^{6}$, R. O. Opoka ${ }^{2,7}$, \\ A. Tagoola7, V. Bandika ${ }^{8}$, A. Mpoya ${ }^{4}$, H. Mnjella 4 , E. Nabawanuka², W. Okiror ${ }^{3}$, M. Nakuya ${ }^{6}$, D. Aromut 6 , \\ C. Engoru ${ }^{6}$, E. Oguda ${ }^{4}$, T. N. Williams ${ }^{1,4}$, J. F. Fraser ${ }^{9}$, D. A. Harrison ${ }^{5}$ and K Rowan ${ }^{5}$ on behalf of the COAST trial \\ group
}

(C) 2021 The Author(s)

\begin{abstract}
Purpose: The life-saving role of oxygen therapy in African children with severe pneumonia is not yet established.

Methods: The open-label fractional-factorial COAST trial randomised eligible Ugandan and Kenyan children aged $>28$ days with severe pneumonia and severe hypoxaemia stratum $\left(\mathrm{SpO}_{2}<80 \%\right)$ to high-flow nasal therapy (HFNT) or low-flow oxygen (LFO: standard care) and hypoxaemia stratum ( $\left.\mathrm{SpO}_{2} 80-91 \%\right)$ to HFNT or LFO (liberal strategies) or permissive hypoxaemia (ratio 1:1:2). Children with cyanotic heart disease, chronic lung disease or $>3 \mathrm{~h}$ receipt of oxygen were excluded. The primary endpoint was $48 \mathrm{~h}$ mortality; secondary endpoints included mortality or neurocognitive sequelae at 28 days.

Results: The trial was stopped early after enrolling 1852/4200 children, including 388 in the severe hypoxaemia stratum (median 7 months; median $\mathrm{SpO}_{2} 75 \%$ ) randomised to HFNT $(n=194)$ or LFO $(n=194)$ and 1454 in the hypoxaemia stratum (median 9 months; median $\mathrm{SpO}_{2} 88 \%$ ) randomised to HFNT $(n=363)$ vs LFO ( $\left.n=364\right)$ vs permissive hypoxaemia $(n=727$ ). Per-protocol $15 \%$ of patients in the permissive hypoxaemia group received oxygen (when $\mathrm{SpO}_{2}<80 \%$ ). In the severe hypoxaemia stratum, 48-h mortality was $9.3 \%$ for HFNT vs. $13.4 \%$ for LFO groups. In the hypoxaemia stratum, 48-h mortality was 1.1\% for HFNT vs. 2.5\% LFO and 1.4\% for permissive hypoxaemia. In the hypoxaemia stratum, adjusted odds ratio for 48-h mortality in liberal vs permissive comparison was 1.16 (0.49-2.74; $p=0.73)$; HFNT vs LFO comparison was $0.60(0.33-1.06 ; p=0.08)$. Strata-specific 28 day mortality rates were, respectively: 18.6, 23.4 and 3.3, 4.1,3.9\%. Neurocognitive sequelae were rare.
\end{abstract}

Conclusions: Respiratory support with HFNT showing potential benefit should prompt further trials.

Keywords: Oxygen, High-flow nasal therapy, African children, Pneumonia, Clinical trial

\footnotetext{
*Correspondence: k.maitland@imperial.ac.uk

${ }^{1}$ Department of Infectious Disease and and Institute of Global Health and Innovation, Division of Medicine, Imperial College, London, UK Full author information is available at the end of the article K. Maitland, S. Kiguli, P. Olupot-Olupot and M. Hamaluba authors contributed equally to this work.
}

\section{实 Springer}




\section{Introduction}

In Africa, severe pneumonia remains the leading cause of mortality in children under 5 years old [1], posing a major disease burden on health systems. The World Health Organization (WHO) recommends presumptive antibiotic treatment and oxygen for those with clinicallydefined severe pneumonia and/or hypoxaemia (peripheral oxygen saturation $\left.\left(\mathrm{SpO}_{2}\right)<90 \%\right)$ [2]. However, the evidence under-pinning the use of oxygen therapy is weak [3] and it is generally poorly targeted using non-specific clinical signs [4] since many paediatric services lack pulse oximeters $[5,6]$. In-hospital mortality among pneumonia cases is high (9-16\%) with hypoxemic children at fivefold greater risk of death $[6,7]$. WHO recommends research on the targeted use of oxygen therapy together with simple, non-invasive methods of respiratory support as costeffective strategies for improving outcome [3], but these have not yet been tested in adequately powered randomised controlled trials $[8,9]$.

A key challenge for the trial design is the significant gap between supply and demand for oxygen in resourcelimited African hospitals. Expense and logistic challenges mean that many lack sustainable provision of bottled oxygen [10], as highlighted in a survey of 231 health facilities (12 African countries) showing only $43 \%$ had an uninterrupted source of oxygen, $24 \%$ had a functioning oxygen concentrator (the WHO-preferred source of oxygen [2]) and an only 81 (35\%) had uninterrupted electricity supply (necessary for oxygen concentrators) [11]. Thus, in many hospitals children with severe pneumonia receive little or no oxygen, whether this contributes to the poor outcomes is unknown.

The Children's Oxygen Administration Strategies Trial (COAST) simultaneously addressed two hypotheses. First, whether liberal oxygenation strategies in children with $\mathrm{SpO}_{2} \geq 80-91 \%$ will decrease mortality (at $48 \mathrm{~h}$ and up to 28 days) compared with a permissive hypoxia strategy. Second, whether respiratory support with high-flow nasal therapy (OptiFlow ${ }^{\mathrm{TM}}$ ) decreases mortality (at $48 \mathrm{~h}$ and up to 28 days) compared with low-flow oxygen delivery (standard care) [12].

\section{Methods}

COAST was a two-stratum multicentre, open, fractionalfactorial RCT (see statistical methods, Supplemental Appendix) conducted in four Ugandan and two Kenyan hospitals. Children aged 28 days to 12 years, hospitalised with a history of respiratory illness and any one of the $2013 \mathrm{WHO}$ clinical definitions of severe pneumonia [13] plus hypoxaemia $\left(\mathrm{SpO}_{2}<92 \%\right)$ were enrolled into either the severe hypoxaemia stratum $\left(\mathrm{SpO}_{2}<80 \%\right)$ or the hypoxaemia stratum $\left(\mathrm{SpO}_{2} 80-91 \%\right)$. Children with

\section{Take home message}

In Africa, in children hospitalised with severe pneumonia with oxygen saturations between 80 and $91 \%$ who did not receive oxygen, mortality assessed at $48 \mathrm{~h}(1.4 \%)$ was comparable to the usual method of oxygen delivery (low-flow oxygen; LFO (2.5\%)) and in those receiving high-flow nasal therapy (HFNT, 1.1\%). The potential impact of HFNT on patient-centred outcomes and on resources, particularly oxygen supplies, should stimulate further exploration particularly in children with severe pneumonia managed in low resource settings.

previous diagnosed but uncorrected cyanotic heart disease, chronic lung disease (excluding asthma), children given oxygen given at another health facility (or $>3 \mathrm{~h}$ at the current hospital) or previous COAST enrolment were excluded. In the severe hypoxaemia stratum, eligible children were randomised (ratio 1:1) to high-flow nasal therapy (HFNT) via OptiFlow ${ }^{\mathrm{TM}}$ or low-flow oxygen delivery (LFO: standard practice). In the hypoxaemia stratum, eligible children were randomised (ratio 1:1:2) to HFNT via OptiFlow $^{\text {TM }}$, LFO delivery (standard practice) or permissive hypoxaemia since pre-existing data indicated no differences in mortality across the $\mathrm{SpO}_{2}$ range $80-89 \%$ $[12,14]$ (see Supplemental Appendix and Trial Protocol).

\section{Screening and randomisation}

Children hospitalised with suspected severe pneumonia were clinically assessed for eligibility including oxygen saturation measurement (BITMOS sat $801+$ ), which are capable of measuring oxygen saturations accurately during motion and low peripheral perfusion. Children eligible for the hypoxaemia stratum required two $\mathrm{SpO}_{2}$ readings of $80-91 \% 5 \mathrm{~min}$ apart. Where prior written consent from parents/legal guardians could not be obtained, ethics committees approved verbal assent with delayed written informed consent as soon as practicable [15]. Otherwise informed written consent was obtained from parents or guardians before randomization. The trial statistician in London generated and kept the sequential randomization list, computer-generated using variably sized permuted blocks stratified by trial centre. Randomisation occurred using consecutively numbered packs containing randomised links to opaque sealed envelopes ensuring allocation concealment.

\section{Study procedures}

Children were managed on general paediatric wards; mechanical ventilation facilities were largely unavailable. Training in triage and emergency paediatric life support was given throughout the trial to optimize case recognition, supportive management and protocol adherence. Basic infrastructural support for emergency care, patient monitors, haemoglobin, glucose and lactate point-of-care 
tests, blood cultures and chest X-rays were provided by the study. A structured clinical case report form was completed at admission and on reviews at $12,4,8,16,24$, 36 and $48 \mathrm{~h}$.

\section{Oxygen therapy and respiratory support}

HFNT was delivered by AIRVO ${ }^{\mathrm{TM}} 2$ device (https://www. fphcare.com/), which contains a humidifier with integrated flow generator that delivers, to spontaneous breathing patients, high flow warmed and humidified air/ oxygen blend. HFNT was initiated on $\mathrm{FiO}_{2}$ of $21 \%$ (room air) with flow rates increase and oxygen titrated in using a structured protocol. Reliable sources of oxygen including electricity power-back up for the $\mathrm{AIRVO}^{\mathrm{TM}} 2$ and oxygen concentrators were provided to ensure oxygen delivery was uninterrupted [11]. LFO was delivered by nasal canulae/prongs and escalated to higher flow rates delivered by standard masks. Saturations were checked at 15-, 30-, and 60-min post-enrolment and during the structured reviews. Per-protocol the permissive hypoxaemia arm received LFO if $\mathrm{SpO}_{2}$ fell below $80 \%$. Children unable to tolerate HFNT were switched to LFO. From 2-h post-enrolment oxygen could be weaned/stopped if $\mathrm{SpO}_{2}$ remained $\geq 92 \%$ in room air and restarted if $\mathrm{SpO}_{2}$ dropped to $<92 \%$. At $48 \mathrm{~h}$ children on HFNT were switched to LFO (extra details in Supplemental Methods).

All children received standard treatments including intravenous maintenance fluids $(2.5-4 \mathrm{mls} / \mathrm{kg} / \mathrm{hour})$ [16], antibiotics, antimalarials, antipyretics, anticonvulsants, and transfusion for haemoglobin $<5 \mathrm{~g} / \mathrm{dl}$ according to national guidelines. At the scheduled follow-up visit, children were clinically assessed (including neurodevelopmental assessment) at 28 day post-randomization. Clinicians were trained on the structured 'Kilifi Developmental Milestones Assessment which covers three broad domains of child functioning: motor, language and personal-social development [17]. From previous experience [18], neurocognitive changes can be transient, children who exhibiting neurocognitive sequalae at 28 days were re-assessed at 90 days. Nurses/doctors were unblinded; laboratory tests were assayed blinded.

\section{Endpoints}

The primary outcome was mortality at 48 -h post-randomization (a timepoint capturing the majority of inpatient deaths [16]) and deaths to Day 28 [19]. Secondary outcomes included day- 28 mortality, treatment failure at $48 \mathrm{~h}$ (persistent hypoxaemia: $\mathrm{SpO}_{2}<92 \%$ plus respiratory distress), time to hypoxaemia resolution $\left(\mathrm{SpO}_{2} \geq 92 \%\right)$, duration of respiratory (oxygen/HFNT) support, length of initial hospital stay, Day-28 neurocognitive/developmental sequelae, re-admissions and anthropometric status (See Statistical Analysis Plan). Adverse events were graded using the Common Toxicity Criteria for Adverse Events v4.0 [20]. An Endpoint Review Committee (ERC) reviewed all deaths blinded to treatment arm.

\section{Statistical analysis}

The sample size was determined using simulations, assuming a 1:2 ratio between the respective strata and $48 \mathrm{~h}$ mortality in the LFO arms of 26 and $9 \%$ in severely hypoxaemia and hypoxaemia strata respectively [12]. Overall, 4200 children provided at least $90 \%$ power to detect a $33 \%$ relative risk reduction (RR) for liberal (HTNT or LFO) vs permissive hypoxaemia and a $25 \%$ RR for HFNT vs. LFO. Two (of three) planned interim analyses were reviewed by an independent Data Monitoring Committee using Haybittle-Peto criterion $(p<0.001)$ for early stopping for either efficacy or harm.

Patients were analysed according to their randomised groups, following a prespecified statistical analysis plan. The primary outcome was analysed as a binary outcome using multilevel logistic regression including both treatment allocation variables simultaneously (HFNT vs. LFO, and liberal (any respiratory support) vs. permissive hypoxaemia and adjusted for the stratifying factors of baseline $\mathrm{SpO}_{2}$ (grouped as $<80,80-84,85-89,90-91 \%$ ) and trial site (as a random factor). Adjusted odds ratios (aOR) with 95\% confidence intervals (CI) were calculated to compare any respiratory support/oxygen vs permissive hypoxaemia (hypoxaemia stratum only), and HFNT vs. LFO (primary effect estimates). Each treatment allocation variable was tested for significance using a likelihood ratio test of the reduced compared to full regression model fit. (More details in Supplemental Methods).

\section{Results}

The trial was stopped prematurely in by the Trial Steering Committee on the grounds of feasibility as a result of a campaign to terminate the trial in Uganda, which deemed permissive hypoxaemia (permissive hypoxaemia) unethical (detailed in the Supplemental Methods).

Between 14th Feb 2017 and when enrolment ceased (28th Feb 2020) 1842 eligible children were enrolled into the COAST trial and included in all analyses (Fig. 1), Of 388 in the severe hypoxaemia stratum, 194 children were randomised to HFNT and 194 to LFO. Of 1454 children in the hypoxaemia stratum, 363 to were randomised to HFNT, 364 to LFO and 727 to permissive hypoxaemia. Baseline characteristics are presented in Table 1 demonstrating multiple features of severe pneumonia were present in all children. In the respective strata median $\mathrm{SpO}_{2}$ was $75(68,78)$ and $88(85,90)$; 75 and $65 \%$ had radiographically confirmed pneumonia. Additional baseline 


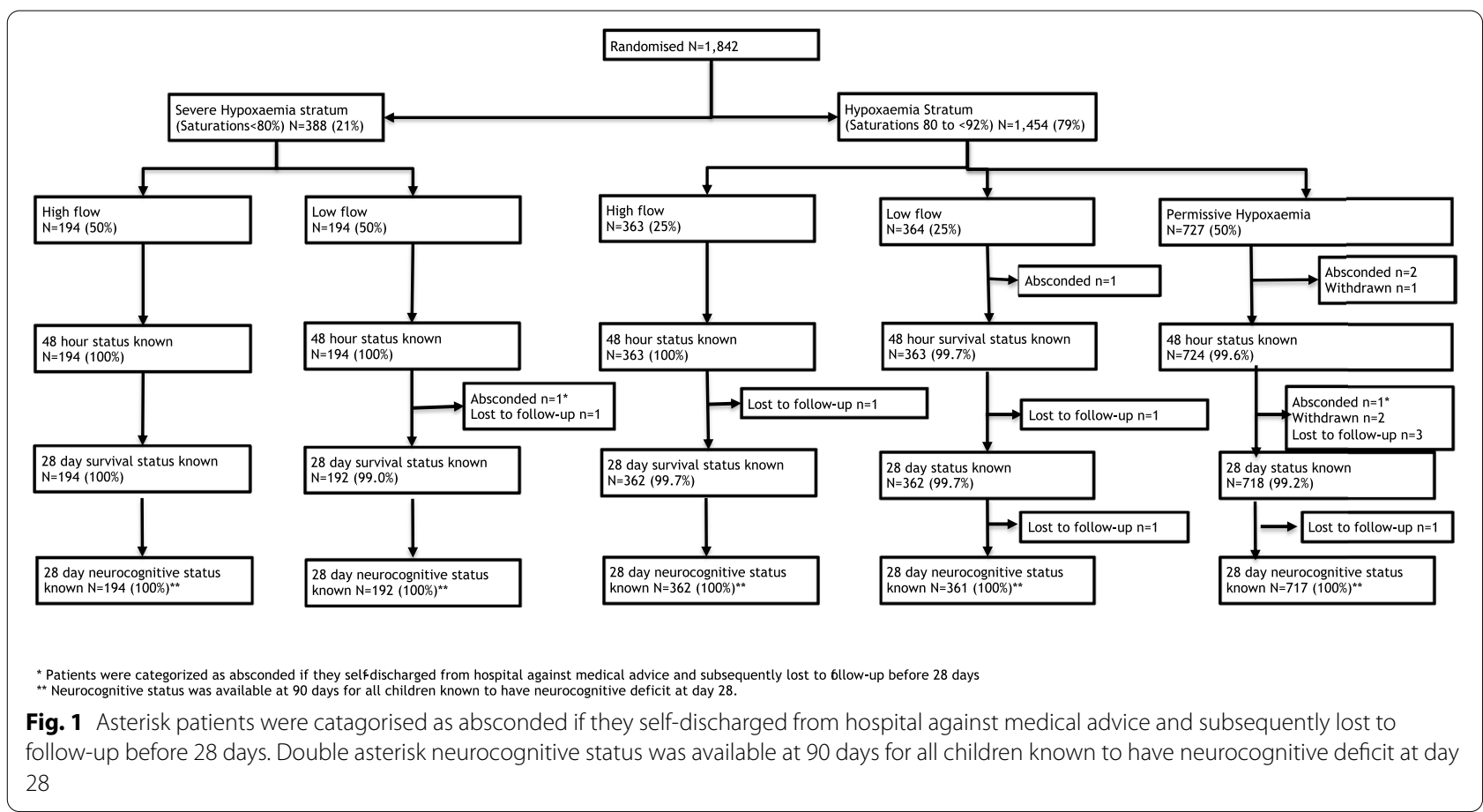

features and working diagnoses reported at $48 \mathrm{~h}$ are summarised in Supplemental Tables S2a, b.

\section{Adherence to randomisation}

Most oxygen therapy was started within $30 \mathrm{~min}$ of screening except for three children on HFNT who died before this timepoint. Adherence to the randomisation strategy was excellent (Table 2). Per protocol LFO was started in the permissive hypoxaemia arm in 107/726 (14.7\%) for drops of $\mathrm{SpO}_{2}<80 \%$ and in 2 whose $\mathrm{SpO}_{2}$ was $>80 \%$. Three children unable to tolerate HFNT were switched to LFO.

\section{Use of oxygen and respiratory support}

In the severe hypoxaemia stratum, median duration (interquartile range, IQR) on respiratory support by HFNT was longer than for LFO $36.6 \mathrm{~h}(9,48)$ versus $32.1 \mathrm{~h}(7.4,47.7)$. In the hypoxaemia stratum duration of support by HFNT and LFO were similar $(8.4(2.8,26.8)$ and $6.8(2.5,25.3)$ hours respectively (Fig. 2; Tables 2 and Supplemental T2). In the hypoxaemia stratum only 198/362 (54.7\%) on HFNT had oxygen titrated in. In the severe hypoxaemia stratum although the number of hours of supplemental air/oxygen blend was similar over the $48 \mathrm{~h}$ period, the mean (standard deviation) volume of oxygen (litres) used was lower in HFNT: 2731L/child (2733) than LFO: 3591L/child (4128). In the hypoxaemia stratum both the time receiving supplemental air/oxygen [9.8 (14.6) versus 15.9 (16.6)] hours and oxygen volume received [969L/child (1890) versus 1481L/child (2480)] were considerably lower in HFNT than LFO. The permissive hypoxaemia strategy had lower hours/volume of oxygen therapy than the liberal strategies. Baseline $\mathrm{SpO}_{2}$ levels in children requiring oxygen in the permissive hypoxaemia arm were similar to those never receiving oxygen (Supplemental Figure S1).

\section{Mortality and neurocognitive sequelae}

Vital status at $48 \mathrm{~h}$ (primary endpoint) was known in all children $388(100 \%)$ in the severe hypoxaemia stratum and in 363 (100\%), 363 (99.7\%) and 724 (99.6\%) in the hypoxaemia stratum children, respectively. By Day 28 vital status was known in $194(100 \%)$ and $192(99 \%)$ in the severe hypoxaemia stratum and in 362 (99.7\%), $362(99.7 \%)$ and 718 (99.2\%) in the hypoxaemia stratum children respectively (Supplemental Figure S2). By $48 \mathrm{~h}$ in the severe hypoxaemia stratum, 18 (9.3\%) in HFNT versus 26 (13.4\%) in LFO groups had died. In the hypoxaemia stratum, $4(1.1 \%), 9(2.5 \%)$ and 10 (1.4\%) children in HFNT vs LFO vs permissive hypoxaemia had died. The aOR for liberal versus permissive hypoxaemia was $1.16(95 \%$ CI $0.49,2.74) p=0.728$ and for HTNT versus LFO was $0.60(0.33,1.06) p=0.076$ (Table 3$)$. By 28 days, 36 (18.6\%) and 45 (23.4\%) children in the severe hypoxaemia stratum and $12(3.3 \%)$, $15(4.1 \%)$ and $28(3.9 \%)$ in the hypoxaemia stratum had died [aOR for LFO versus permissive hypoxaemia $0.92(0.53,1.59)$; aOR for HFNT versus LFO was 0.75 
Table 1 Characteristics of children at baseline by study stratum

\begin{tabular}{|c|c|c|c|c|c|}
\hline \multirow[b]{2}{*}{ Parameter } & \multicolumn{2}{|c|}{$\begin{array}{l}\text { Severe hypoxaemia stratum } \\
\left.\text { (Saturations } \mathrm{SpO}_{2}<80 \%\right)\end{array}$} & \multicolumn{3}{|c|}{$\begin{array}{l}\text { Hypoxaemia stratum } \\
\left.\text { (Saturations } \mathrm{SpO}_{2} 80 \text { to }<92 \%\right)\end{array}$} \\
\hline & $\begin{array}{l}\text { HFNT } \\
(n=194)\end{array}$ & $\begin{array}{l}\text { Low-flow } \\
(n=194)\end{array}$ & $\begin{array}{l}\text { HFNT } \\
(n=363)\end{array}$ & $\begin{array}{l}\text { Low-flow } \\
(n=364)\end{array}$ & $\begin{array}{l}\text { Permissive hypoxaemia } \\
(n=727)\end{array}$ \\
\hline Median age, months (IQR) & $7(2-21)$ & $7(2-16)$ & $9(4-24)$ & $9(4-22)$ & $10(4-25)$ \\
\hline Male sex $n(\%)$ & $93(47.9)$ & $97(50)$ & $213(58.7)$ & $214(58.8)$ & $422(58)$ \\
\hline Median $\mathrm{SpO}_{2}(\mathrm{IQR})$ & $75(68-78)$ & $75(66-77)$ & $88(86-89)$ & $88(86-09)$ & $88(86-90)$ \\
\hline $\begin{array}{l}\mathrm{SpO}_{2}<70 \% \text { (severe hypoxaemia stratum) } \\
\text { or }<85 \% \text { (hypoxaemia stratum) } n(\%)\end{array}$ & $55(28.4)$ & $60(30.9)$ & $60(16.5)$ & 65 (17.9) & $98(13.5)$ \\
\hline Median weight, kg (IQR) & $6.8(4.8-10)$ & $6.6(4.8-9)$ & $8.1(6.4-11)$ & $7.9(6.2-10.4)$ & $8.3(6.5-10.8)$ \\
\hline Median MUAC, cm (IQR) & $13(11.4-14.2)$ & $13(11.5-14.2)$ & $14(13-15)$ & $13.7(12.7-14.7)$ & $14(12.8-15)$ \\
\hline Fever $\left(>37.5^{\circ} \mathrm{C}\right) n(\%)$ & $105(54.1)$ & $94(48.5)$ & $191(52.6)$ & $188(51.6)$ & $341(46.9)$ \\
\hline Hypothermia $\left(<36^{\circ} \mathrm{C}\right)$ & $5(2.6)$ & $13(6.7)$ & $4(1.1)$ & $9(2.5)$ & $20(2.8)$ \\
\hline Respiratory rate (IQR) & $65(56-79)$ & $66.5(56-79)$ & $61(52-69)$ & $60(52-68)$ & $60(51-67)$ \\
\hline Tachypnoea $n(\%)$ & $178(91.8)$ & $176(90.7)$ & $330(90.9)$ & $331(90.9)$ & $654 / 726(90.1)$ \\
\hline Indrawing $n / N(\%)$ & 186/193 (96.4) & 187/193 (96.9) & $334(92)$ & $343(94.2)$ & $658(90.5)$ \\
\hline Cyanosis n/N (\%) & 13/192 (6.8) & $15(7.7)$ & $3(0.8)$ & $3(0.8)$ & $4(0.6)$ \\
\hline Crepitations n/N (\%) & 136/192 (70.8) & $149(76.8)$ & $271(74.7)$ & $267(73.4)$ & $530 / 725(73.1)$ \\
\hline Wheeze $n / N(\%)$ & $42 / 191(22)$ & $37(19.1)$ & $91 / 362(25.1)$ & $93(25.5)$ & $182 / 723(25.2)$ \\
\hline Pneumonia signs on chest X-ray $n / N(\%)$ & 128/165 (77.6) & 113/155 (72.9) & $227 / 347(65.4)$ & $217 / 342(63.5)$ & $426 / 695(66.3)$ \\
\hline Severe tachycardia $n / N(\%)$ & $72(37.1)$ & $77(39.7)$ & $90 / 362(24.9)$ & $100(27.5)$ & $17924.6)$ \\
\hline Compensated shock n/N (\%) & 118/193 (61.1) & $121(62.4)$ & $139(38.3)$ & $145(39.8)$ & $287(39.5)$ \\
\hline Severe pallor $n / N(\%)$ & $31 / 193(16.1)$ & $24(12.4)$ & $36(9.9)$ & $26(7.1)$ & $57(7.8)$ \\
\hline Vomiting/diarrhoea n/N (\%) & $62 / 193(32.1)$ & $67(34.5)$ & $120 / 362(33.1)$ & $136(37.4)$ & 239/726 (32.9) \\
\hline Dehydrated $n / N(\%)$ & $11 / 191(5.8)$ & $20(10.3)$ & $11(3)$ & $15 / 363(4.1)$ & $22 / 725(3)$ \\
\hline \multicolumn{6}{|l|}{ Conscious level: responds to } \\
\hline Pain or voice $n / N(\%)$ & $33(17)$ & $24(12.4)$ & $14(3.9)$ & 14/363(3.9) & $26(3.6)$ \\
\hline Unresponsive $n / N(\%)$ & $8(4.1)$ & $13(6.7)$ & $2(0.6)$ & $3 / 363(0.8)$ & $3(0.4)$ \\
\hline Severely malnourished $n / N(\%)$ & 19/193 (9.8) & $29(14.9)$ & $10(2.8)$ & $24 / 362(6.6)$ & $33 / 726(4.5)$ \\
\hline Sickle cell disease $n / N(\%)$ & $10(5.2)$ & $7(3.6)$ & $26(7.2)$ & $26(7.1)$ & $40(5.5)$ \\
\hline Developmental delay $n / N(\%)$ & $16 / 193(8.3)$ & $16(8.2)$ & $21(5.8)$ & $17 / 362(4.7)$ & $40(5.5)$ \\
\hline Median haemoglobin, g/dl (IQR) & $9.6(7.3-11.1)$ & $10.2(8.7-11.3)$ & $10.2(8.8-11.4)$ & $10.3(8.9-11.4)$ & 10.4(8.9-11.7) \\
\hline Severe anaemia $(\mathrm{Hb}<5 / \mathrm{dl}) n / N(\%)$ & 24/184 (13) & 13/182 (7.1) & $33 / 352(9.4)$ & $26 / 348(7.5)$ & $59 / 698(8.5)$ \\
\hline White cell count $(10 \times 3 / \mu \mathrm{L})$ median $(\mathrm{IQR})$ & $13.9(9.5-20.3)$ & $13.2(9.4-18.7)$ & $12.5(9.2-17.3)$ & $11.9(8.3-16.4)$ & $11.9(8.3-17.9)$ \\
\hline Leucocytosis (WBC> 11) n/N (\%) & $120 / 184(65.2)$ & $117 / 182(64.3)$ & 204/351 (58.1) & 193/347 (55.6) & $388 / 698(55.6)$ \\
\hline$H^{\prime a}{ }^{a} n(\%)$ & $6 / 188(3.2)$ & $11 / 188(5.9)$ & $4 / 354(1.1)$ & $15 / 356(4.2)$ & 13/707 (1.8) \\
\hline Malaria RDTa $n / N(\%)$ & 25/187 (13.4) & 18/181 (9.9) & $49 / 350(14)$ & $38 / 352(10.8)$ & $98 / 700(14)$ \\
\hline Malaria slide positive $n$ (\%) & 11/187(5.9) & 13/182 (7.1) & 26/354 (7.3) & $15 / 354(4.2)$ & $36 / 700(5.1)$ \\
\hline Bacteraemia $n / N(\%)$ & 10/187 (5.3) & $7 / 183(3.8)$ & $8 / 354(2.3)$ & $8 / 353(2.3)$ & 19/705 (2.7) \\
\hline Hypoglycaemia (glucose < 3/mmol/L) $n(\%)$ & 10/192 (5.2) & $9 / 193(4.7)$ & $7(1.9)$ & $5(1.4)$ & $21 / 727(2.9)$ \\
\hline Lactate $>5$ mmol/L $n / N(\%)$ & $41 / 191(21.5)$ & $38 / 190(20)$ & $34 / 354(9.6)$ & 21/358 (5.9) & $54 / 715(7.6)$ \\
\hline Antibiotics in illness n/N (\%) & $112 / 186(60.2)$ & 121/192 (63) & 205/358 (57.3) & 201/358 (56.1) & $404 / 721(56)$ \\
\hline Antimalarial in Illness $n / N(\%)$ & $41 / 188(21.8)$ & $42 / 190(22.1)$ & 97/361 (26.9) & $85 / 363(23.4)$ & 169/726 (23.3) \\
\hline
\end{tabular}

${ }^{a}$ Missing not valid, not done/recorded

$(0.49,1.16)]$. Most neurocognitive sequelae primarily reported at Day 28 in survivors were transient, and all had resolved by Day 90. Details on blind ERC review of deaths and relationship are given in Table 3. Overall, there was one event identified by this process that was possibly related to treatment arm; most deaths appeared to be attributable to the severity of the underlying condition or comorbidity. 
Table 2 Respiratory support and oxygen use per randomised strategy

\begin{tabular}{|c|c|c|c|c|c|}
\hline & \multicolumn{2}{|c|}{$\begin{array}{l}\text { Severe hypoxaemia stratum } \\
\text { (Saturations }<80 \% \text { ) }\end{array}$} & \multicolumn{3}{|c|}{$\begin{array}{l}\text { Hypoxaemia stratum } \\
\text { (Saturations } 80 \text { to }<92 \% \text { ) }\end{array}$} \\
\hline & HFNT & Low flow & HFNT & Low-flow & Permissive hypoxaemia \\
\hline Number of participants & 194 & 194 & 363 & 364 & 727 \\
\hline Initiated allocated treatment ${ }^{\mathrm{a}}, \mathrm{n} / \mathrm{N}(\%)$ & 192/194 (99) & 194/194 (100) & $362 / 363(99.7)$ & $362 / 364(99.5)$ & 726/727 (99.9) \\
\hline Protocol deviation ${ }^{b}$ & 0 & 0 & 1 & 2 & 2 \\
\hline Received oxygen $\left(\mathrm{FiO}_{2}>21 \%\right)$ ever, $n / \mathrm{N}(\%)$ & 182/192 (93.8) & 194/194 (100) & $198 / 362(54.7)$ & $364 / 364(100)$ & 109/726 (15) \\
\hline Interruptions with treatment strategyc $n / N(\%)$ & 3/192 (1.6) & 2/194 (1) & $9 / 362(2.5)$ & $7 / 362(1.9)$ & \\
\hline Starting flow rate I/min, median (IQR) & $14(10,20)$ & $1(1,2)$ & $16(13,22)$ & $1(1,2)$ & \\
\hline Max flow rate, median (IQR) & $14(10,20)$ & $2(1.5,3)$ & $16(13,22)$ & $1.5(1,2)$ & \\
\hline Initiated treatment with $\mathrm{FiO}_{2}>21 \%, n / N(\%)$ & 49/192 (25.5) & 194/194 (100) & $3 / 362(0.8)$ & 363/364 (99.7\%) & \\
\hline \multicolumn{6}{|l|}{ In the first $48 \mathrm{~h}$} \\
\hline Hours of respiratory support ${ }^{\mathrm{d}}$, mean (sd) & $30.4(18.6)$ & $28(18.8)$ & $17(17.2)$ & $15.9(16.6)$ & $3.5(10.6)$ \\
\hline Hours of respiratory support ${ }^{\mathrm{d}}$, median (IQR) & $36.6(9,48)$ & $32.1(7.4,47.7)$ & $8.4(2.8,26.8)$ & $6.8(2.5,25.3)$ & $0(0,0)$ \\
\hline Hours receiving additional oxygen ${ }^{d}$, mean (sd) & $28.1(18)$ & $28(18.8)$ & $9.8(14.6)$ & $15.9(16.6)$ & $3.5(10.6)$ \\
\hline Hours receiving additional oxygen ${ }^{d}$, median (IQR) & $33.1(8.3-46.7)$ & $32.1(7.4,47.7)$ & $1(0,18.7)$ & $6.8(2.5,25.3)$ & $0(0,0)$ \\
\hline Litres of oxygen used ${ }^{d}$, mean (sd) & $2731(2733)$ & $3591(4128)$ & $969(1890)$ & $1481(2480)$ & $359(1273)$ \\
\hline Litres of oxygen used ${ }^{\mathrm{d}}$, median (IQR) & $1983(502,3571)$ & $2743(895,4884)$ & $113(0,1454)$ & $480(236,2132)$ & $0(0,0)$ \\
\hline Any dose escalation $n(\%)$ & $174(89.7)$ & $165(85.1)$ & $222(60.2)$ & $178(48.9)$ & $109(15)$ \\
\hline
\end{tabular}

This table reports hours of treatment (and oxygen usage) for all children randomised to the specific strategies

a Two patients in the severe hypoxaemia stratum and one patient in the hypoxaemia stratum died before they started HFNT, one patient in permissive hypoxaemia arm absconded numbers initiated are revised according

b Protocol deviation The hypoxaemia stratum: HFNT: one patient switched to low flow before $48 \mathrm{~h}$; low flow: two patients started on HFNT; permissive hypoxaemia: two initiated low-flow oxygen at $\mathrm{SpO}_{2} \geq 80 \%$

c Interruptions in oxygen treatment strategy: high-flow (both strata): power cuts $(n=2)$, child unable to tolerate $(n=4)$, nasal/facial trauma ( $n=1)$ and child on nebulisation with $>15 \mathrm{~min}$ off $\mathrm{O}_{2}$ therapy $(n=5)$. Low-flow (both strata): child unable to tolerate $(n=1)$, child on nebulisation with $>15$ min off $\mathrm{O}_{2}$ therapy $(n=7), 1$ child not specified

${ }^{d}$ Hours of support and litres of $\mathrm{O}_{2}$ are summarised over all patients, those never receiving support/oxygen are assigned values of 0

\section{Other clinical outcomes}

Treatment failure to $48 \mathrm{~h}$ (defined as $\mathrm{SpO}_{2}<92 \%$ plus respiratory distress) was somewhat lower in HFNT versus LFO aOR $0.75(0.40,1.41)$ and lower for liberal versus permissive hypoxaemia strategy aOR $0.37(0.19,0.71)$ (Table 3; Supplemental Figure S3). Further exploration of these treatment failures by severity of hypoxaemia $(<80$, 80-89 and 90-91\%) and comorbidities are reported in Supplemental Table S3. Overall, in the severe hypoxaemia stratum, $14 / 33(42.4 \%)$ and $12 / 33(36 \%)$ treatment failures were for saturations of $<80$ and $80-89 \%$, respectively. Day-28 hospital readmissions were low $(\leq 3 \%)$ across all groups/strata (Supplemental Table S4). There was no evidence of a difference in mean hospital stay in the HFNT versus LFO [difference in means 0.26 (95\% $\mathrm{CI}-0.43,0.94)]$ or liberal versus permissive hypoxaemia $[0.62(0.02,1.22)]$ groups nor differences in anthropometric status at Day 28 (Table 3).

\section{Discussion}

The premature termination of the COAST trial meant that it was unable answer the two specific hypotheses it was designed to address. First, whether liberal oxygenation therapy for children with hypoxaemia $\left(\mathrm{SpO}_{2}\right.$ $80-91 \%)$ is superior to permissive hypoxaemia. In this stratum, however, the overall $48 \mathrm{~h}$ and Day 28 mortality was low across all arms including the permissive hypoxaemia arm. Second, as the trial was stopped prematurely there were insufficient data to demonstrate that HFNT was superior to LFO, but caution that the interpretation may be subject to a Type II error i.e. false negative (no benefit of HFNT versus LFO) since it was underpowered to uncover true effects, should they exist. However, the size of reduction $(40 \%)$ in 48 -h mortality warrants further investigation particularly for children with severe hypoxaemia $\left(\mathrm{SpO}_{2}<80 \%\right)$. Notably, across both strata the method of HFNT administration was also relatively oxygen-sparing, using room air/oxygen blends without any evidence of harm. In the hypoxaemia stratum in many cases HFNT was provided on room air, leading to correction of hypoxaemia, without any evidence of harm.

Although the trial does not provide definitive data to inform treatment guidelines, the knowledge acquired from the trial adds a new level of uncertainty to the liberal use of oxygen as a supportive therapy [21]. Equipoise, centred on the degree of uncertainty about the relative 


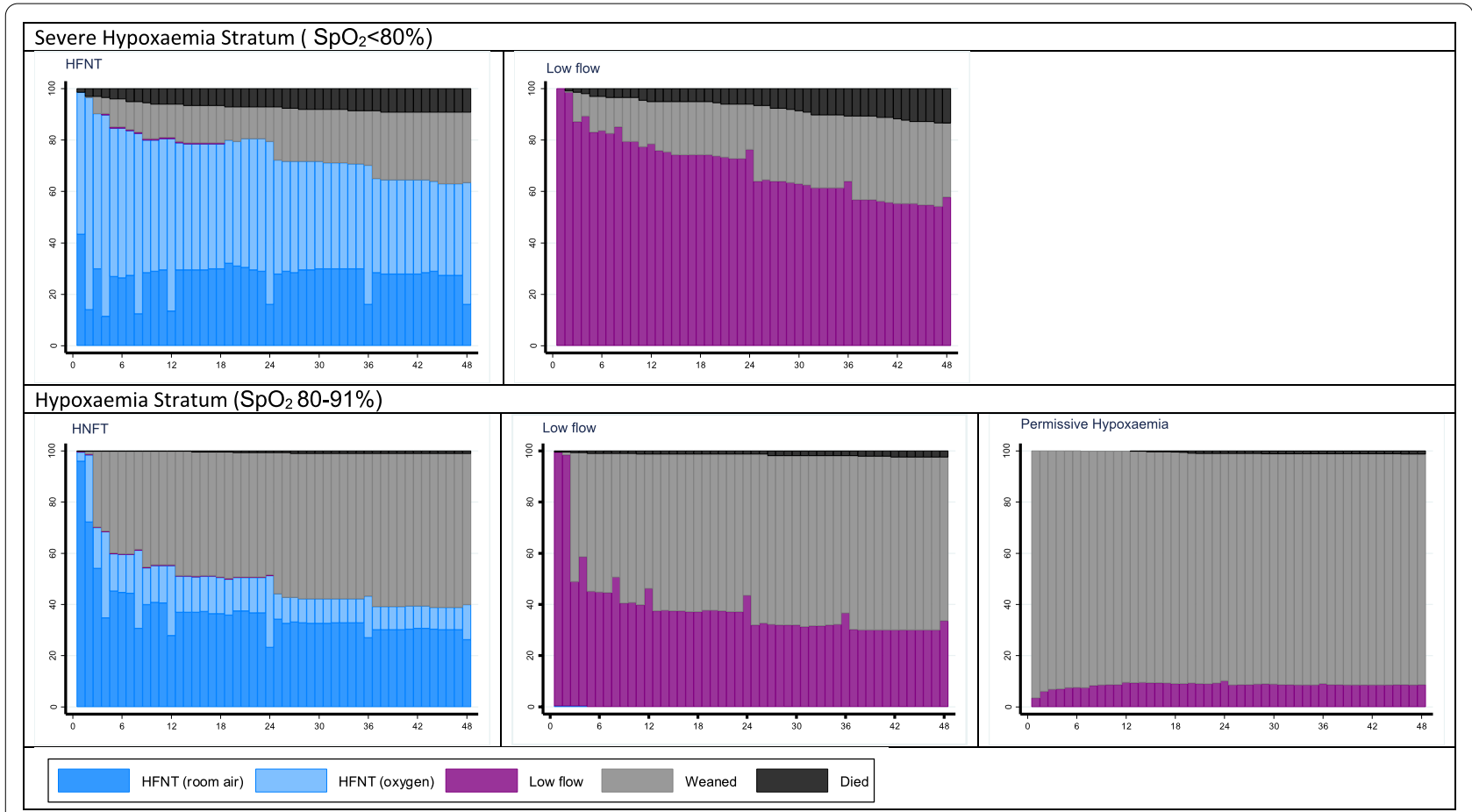

HFNT (room air: $\mathrm{FiO}_{2}=215$ ); HFNT (oxygen: O2/Room air blend) Weaned: not receiving any respiratory support at this timepoint

Fig. 2 Proportion of children in each stratum receiving oxygen/respiratory support by group over 48- hours post-randomisation

benefits (or risks) of a clinical intervention, requires a clear distinction between pre-existing knowledge (evidence) and opinion or personal preference [22]. In the case of severe pneumonia, pre-existing evidence demonstrating clear benefits of oxygen therapy was poor [3]. On that basis the trial was both ethically and scientifically sound [23]. Substantial uncertainty behoves clinicians to conduct RCTs so that in future societies will know which treatments are better and ensuring patients will not be exposed to inferior or harmful treatments.

Whilst oxygen, as a supportive therapy, has been considered the standard treatment for pneumonia for a large part of the last century, the recognition of potential oxygen toxicity is relatively recent [24]. In several areas of emergency care and resuscitation, the use of oxygen (and other therapies included in guidelines [25]) are now being challenged by emerging evidence from clinical trials, including in paediatric populations [26, 27], and in systematic reviews $[21,28]$. In neonates, medical oxygen used during resuscitation increases mortality, myocardial injury and renal injury [29].

COAST was designed with cognisance of the significant gaps between supply and demand for oxygen in hospitals in developing countries [11]. Sustainable provision of bottled oxygen is expensive and logistically challenging
[30]; therefore, the WHO-preferred source of oxygen is oxygen concentrators [2]. Nevertheless, technical reports on the operational quality, availability and reliability of cylinders and oxygen concentrators indicate that, even when available, these are often faulty and unsustainable due to high cost [10], or depend upon erratic electricity supply [11]. With regard to demand on health services, the routine use of pulse oximetry to target oxygen therapy is poorly implemented despite having been recommended by WHO for triage of sick children for over two decades [5]. Hence, oxygen therapy is generally targeted by non-specific clinical signs that predict hypoxaemia poorly [4], thus exposing large numbers of children without hypoxaemia to oxygen therapy, and raising questions over safety $[28,31]$, cost and demand for a constrained health resource [32]. Our findings indicating that hypoxaemia in children with severe pneumonia can be corrected without additional oxygen (including those on HFNT using room air alone) is timely given the major demand on health services for oxygen therapy as a result of the COVID-19 epidemic.

Recognising the resource limitations and costs of oxygen therapy, the protocol incorporated relatively oxygensparing strategies in the investigational groups (HFNT and permissive hypoxaemia) and vital sign monitoring 
Table 3 Primary and secondary endpoints

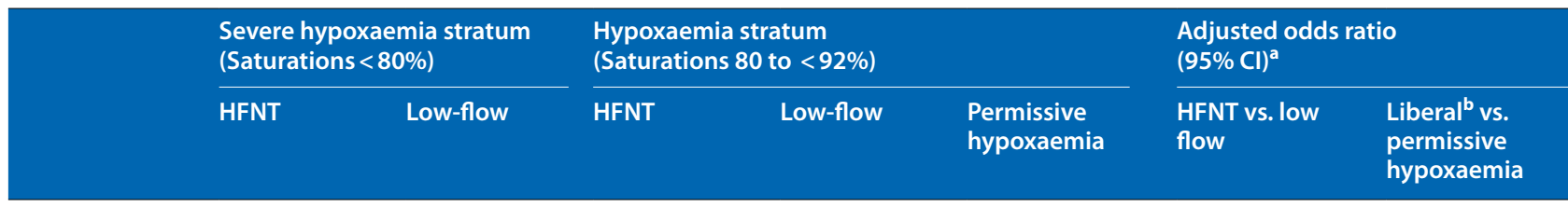

\section{At 48 hours}

\begin{tabular}{|c|c|c|c|c|c|c|c|}
\hline $\begin{array}{l}\text { Death (primary } \\
\text { outcome) } n / N \\
(\%)\end{array}$ & 18/194 (9.3) & 26/194 (13.4) & 4/363 (1.1) & $9 / 363(2.5)$ & 10/724 (1.4) & $\begin{array}{c}0.60(0.33,1.06) \\
(p=0.076)^{* *}\end{array}$ & $\begin{array}{c}1.16(0.49,2.74) \\
\quad(p=0.728)\end{array}$ \\
\hline Treatment failure & 15/175 (8.6) & 18/167 (10.8) & $5 / 359(1.4)$ & $8 / 353(2.3)$ & 33/711 (4.6) & $0.75(0.4,1.41)$ & $0.37(0.19,0.71)$ \\
\hline $\begin{array}{l}\text { Treatment failure } \\
\text { or death }\end{array}$ & $33 / 193$ (17.1) & 44/193 (22.8) & $9 / 363(2.5)$ & $17 / 362(4.7)$ & 43/721 (6) & $0.64(0.41,0.99)$ & $0.55(0.33,0.91)$ \\
\hline \multicolumn{8}{|l|}{ At 28 days } \\
\hline Death $n / N(\%)$ & 36/194 (18.6) & 45/192 (23.4) & $12 / 362(3.3)$ & $15 / 362(4.1)$ & 28/718 (3.9) & $0.75(0.49,1.16)$ & $0.92(0.53,1.59)$ \\
\hline $\begin{array}{l}\text { Hospital read- } \\
\text { mission }\end{array}$ & 2/158 (1.3) & 2/147 (1.4) & $7 / 350(2)$ & 5/347 (1.4) & 21/691 (3) & $1.26(0.46,3.42)$ & $0.56(0.27,1.15)$ \\
\hline $\begin{array}{l}\text { Neurocognitive } \\
\text { sequelae }\end{array}$ & $6 / 158$ (3.8) & $8 / 147(5.4)$ & $9 / 350(2.6)$ & $11 / 346(3.2)$ & $16 / 689(2.3)$ & $0.74(0.37,1.48)$ & $1.23(0.63,2.4)$ \\
\hline \multirow{2}{*}{$\begin{array}{l}\text { Death or neu- } \\
\text { rocognitive } \\
\text { sequelae }\end{array}$} & 42/194 (21.6) & $53 / 192$ (27.6) & $21 / 362(5.8)$ & 26/361 (7.2) & 44/717 (6.1) & $0.74(0.51,1.08)$ & $1.04(0.67,1.59)$ \\
\hline & & & & & & \multicolumn{2}{|c|}{$\begin{array}{l}\text { Adjusted difference in means }{ }^{a} \\
(95 \% \mathrm{Cl})\end{array}$} \\
\hline $\begin{array}{l}\text { Weight for age } \\
\text { z score, mean } \\
\text { (s.d.) }[N]\end{array}$ & $-0.4(1.8)[141]$ & $-0.6(1.8)[136]$ & -0 (1.7) [307] & $-0.2(1.6)[311]$ & $-0.2(1.6)[633]$ & $0.05(-0.05,0.16)$ & $0.04(-0.05,0.13)$ \\
\hline $\begin{array}{l}\text { Mid-upper arm } \\
\text { circumference } \\
\text { z score, mean } \\
\text { (s.d.) }[N]\end{array}$ & $-0.8(1.3)$ [93] & $-0.7(1.4)$ [94] & $-0.1(1.4)[251]$ & $-0.3(1.3)[257]$ & $-0.2(1.3)[528]$ & $0.08(-0.11,0.27)$ & $0.02(-0.14,0.17)$ \\
\hline $\begin{array}{l}\text { Length of stay } \\
\text { mean (s.d.) }[N]\end{array}$ & 6.3 (5.6) [194] & $6.2(6.1)$ [194] & 5.3 (10.4) [363] & $4.9(3.7)[364]$ & 4.5 (2.9) [726] & $0.26(-0.43,0.94)$ & $0.62(0.02,1.22)$ \\
\hline \multicolumn{8}{|c|}{ Serious adverse event } \\
\hline $\begin{array}{l}\text { At least one } \\
\text { event no. of } \\
\text { patients (\%) }\end{array}$ & 42/194 (21.6) & 48/194 (24.7) & 26/363 (7.2) & 26/364 (7.1) & $52 / 727(7.2)$ & & \\
\hline $\begin{array}{l}\text { Number of } \\
\text { events }\end{array}$ & 80 & 88 & 49 & 51 & 85 & & \\
\hline
\end{tabular}

\section{Endpoint Review Committee adjudication fatal events relationship to supplemental oxygen ${ }^{\mathrm{b}}$}

\begin{tabular}{llll} 
Not reviewed & 2 & 1 & 3 \\
\hline $\begin{array}{l}\text { Unlikely/unre- } \\
\text { lated }\end{array}$ & 14 & 13 & 26 \\
$\begin{array}{l}\text { Insufficient } \\
\text { information }\end{array}$ & 0 & 1 & 0 \\
\hline
\end{tabular}

\section{Endpoint Review Committee adjudication fatal events relationship to delivery method}

\begin{tabular}{cccccc} 
Not reviewed & 3 & 6 & 2 & 0 & 1 \\
$\begin{array}{c}\text { Unlikely/unre- } \\
\text { lated }\end{array}$ & 36 & 39 & 14 & 15 & 27 \\
Possibly related & 0 & 0 & 0 & 0 & 1 \\
\hline
\end{tabular}

$\sim$ Treatment failure defined as $\mathrm{SpO}_{2}<92 \%$ in the presence of respiratory distress at $48 \mathrm{~h}$ post-randomisation

a Adjusted for initial $\mathrm{SpO}_{2}$ level (categorised as $<80,80-84,85-89,90-91 \%$ ) and centre (as a random effect), using a GLM

b In this comparison liberal strategies include HFNT and LFO (versus permissive hypoxaemia)

** Unadjusted OR high flow vs. low flow $0.61(95 \% \mathrm{Cl} 0.36,1.06)$, liberal oxygenation vs. permissive hypoxaemia 1.30 (95\% Cl 0.57, 2.99$)$ 
to ensure early weaning in both liberal (HFNT and LFO) strategies (Supplemental Figure S4). Thus, over $48 \mathrm{~h}$ even in the most liberal of the strategies (LFO) the median volume of oxygen in the respective strata (3279 and $1337 \mathrm{~L} /$ child) were substantially lower than in a LFO equivalent strategy (5990L over a median of 2.5 days) reported in the multicentre study in Nigeria investigating oxygen use in children with pneumonia [6].

One key limitation of the COAST trial was its premature termination. Nevertheless, the COAST trial represents the largest trial of oxygen therapy ever conducted in children and the only multicentre controlled trial. Another limitation was that we were unable to confirm the pulse oximetry readings with arterial blood gases. We chose BITMOS sat $801+$, since it incorporates Masimo Signal Extraction Technology ${ }^{\circledR}$ and was the instrument of choice in the large multicentre pneumonia aetiology study [19]. The substantially lower mortality in both strata of the trial, contrast to the mortality rates of 9-10 and $26-30 \%$, respectively, reported in previous studies in African children, on which our power calculation was based $[4,6,7,33]$. Most were conducted prior to the introduction of vaccines against the lead bacterial causes of paediatric pneumonia (Haemophilus influenzae type $\mathrm{b}$ and Streptococcus pneumoniae) into national immunization programs (including Uganda and Kenya) and/or the scaling-up of prevention and anti-retroviral medications for HIV. The resultant change in the aetiologic profile of childhood pneumonia was recently demonstrated by a multi-country case-control hypoxaemia studies of HIV-negative children with radiologically-confirmed pneumonia. Only $56 / 1749(3 \cdot 2 \%)$ cases had a positive blood culture and viruses accounted for $61 \%$ of cases. Respiratory syncytial virus, which is associated with low mortality [34], was the commonest pathogen [19]. The WHO severe pneumonia definition maximizes sensitivity over specificity, resulting in substantial overlap with other medical conditions $[4,35]$. Notable in the COAST trial was the large proportion of previously undiagnosed cardiac conditions particularly in the sub-group with treatment failure. Nevertheless, radiologically confirmed pneumonia was present in a very large proportion of our study population, thus generalisable to children hospitalised with acute pneumonia in resource-limited hospitals.

HFNT has been shown in other populations to reduce the need for mechanical ventilation [36]. In that vast majority of hospitals in Africa access to mechanical ventilation or specialist intensive care is not standard. We, therefore, proposed that HFNT was a feasible alternative source of respiratory support owing to its relative simplicity in implementation, humidification, low risk of nosocomial infection [37]. In addition, the ability to blend both oxygen and room air to deliver positive end-expiratory pressure, thus, limiting exposure to high concentrations of oxygen (and potential toxicity) and with the prospect of reducing costs to health services. Bubble continuous positive airway pressure (bCPAP) is an alternative means of providing respiratory support. However, a recent trial in Malawian children showing worse outcomes in children receiving bCPAP than usual care advocates caution regarding implementation of bCPAP in a real-world setting without physician oversight [9].

In conclusion, our findings support the need for future trials with similar designs, particularly in settings where access to oxygen and/or mechanical respiratory support are restricted. The scale of the mortality reduction of HFNT over LFO, particularly in severely hypoxaemic children $(40 \%)$ warrants further investigation. Oxygen-sparing strategies potentially offer cost-effective approaches to reducing overall oxygen requirements in overburdened health services and adds to the general findings in critical care than 'less is more' [38].

Supplementary Information

The online version contains supplementary material available at https://doi. org/10.1007/s00134-021-06385-3.

\section{Author details \\ ${ }^{1}$ Department of Infectious Disease and and Institute of Global Health and Innovation, Division of Medicine, Imperial College, London, UK. ${ }^{2}$ School of Medicine, Makerere University and Mulago Hospital Kampala, Kampala, Uganda. ${ }^{3}$ Faculty of Health Sciences, Mbale Campus and Mbale Regional Referral Hospital Mbale (POO, WO), Busitema University, Mbale, Uganda. ${ }^{4}$ Kilifi County Hospital and Kenya Medical Research Institute (KEMRI) Wellcome Trust Research Programme, Kilifi, Kenya. ${ }^{5}$ Intensive Care National Audit and Research Centre, London, UK. ${ }^{6}$ Soroti Regional Referral Hospital, Soroti, Uganda. ${ }^{7}$ Jinja Regional Referral Hospital Jinja, Jinja, Uganda. ${ }^{8}$ Coast General District Hospital, Mombasa, Kenya. ${ }^{9}$ Critical Care Research Group and Inten- sive Care Service, University of Queensland, The Prince Charles Hospital, Brisbane, Australia.}

\section{Acknowledgements}

We thank all the participants and staff from all the centres participating in the COAST trial. A special thank to: A. Turnbull, A. Odit (Endpoint Review Committe); E. Molyneux (chair), I. Lubega, W. Macharia, J. Crawley, M. Peters (Trial Steering Committee); T. Peto (chair), P. Musoke, F. Were, C. Semple, J. Todd (Data Monitoring Committee). This paper is published with permission from the Director of KEMRI. We thank the independent members of the trial steering committee and data monitoring committee for their support.

\section{Author's contributions}

KM, KR, DAH, POO, SK, and JF designed the study; SK POO, MH, FA, ROO, AT, VB, AM, HM, WO, MN, CE, EO, and TNW gathered the data; KT/DAH analyzed the data; all authors vouch for the data and analysis; KM wrote the original draft paper which all authors commented on; all authors decided to publish.

\section{Funding}

COAST was funded by the UK Joint Global Health Trials scheme: Medical Research Council, Foreign Commonwealth and Department Office, Department of Health and Social Care through the National Institute for Health Research) and Wellcome Trust (Grant Number MR/L004364/1). Fisher and Paykel Healthcare donated the AIRVO ${ }^{\mathrm{TM}} 2$ machines and oxygen interfaces for the trial.

The funders and the sponsor (Imperial College, London) had no role in study design, data collection, data analysis, data interpretation, or report writing. 


\section{Data availability}

The datasets used and/or analysed during the current study are available from the corresponding author on reasonable request.

\section{Declarations}

\section{Conflict of interest}

All authors declare no conflicts of interest.

\section{Ethical approval}

The School of Medicine Research Ethics Committee, Makerere University, Kampala, Uganda, Kenya Medical Research Institute Scientific Ethics and Review Unit, Nairobi, Kenya and Imperial College Research Ethics Committee approve the trial.

\section{Consent for publication}

We did not obtain consent to publish individual data and were unable to obtain or retrospectively seek consent from individual patients or their legal guardians for the publication of their data. All data were anonymised prior to publication.

\section{Open Access}

This article is licensed under a Creative Commons Attribution 4.0 International License, which permits use, sharing, adaptation, distribution and reproduction in any medium or format, as long as you give appropriate credit to the original author(s) and the source, provide a link to the Creative Commons licence, and indicate if changes were made.

The images or other third party material in this article are included in the article's Creative Commons licence, unless indicated otherwise in a credit line to the material. If material is not included in the article's Creative Commons licence and your intended use is not permitted by statutory regulation or exceeds the permitted use, you will need to obtain permission directly from the copyright holder.

To view a copy of this licence, visit http://creativecommons.org/licenses/by/4. $0 \%$.

\section{Publisher's Note}

Springer Nature remains neutral with regard to jurisdictional claims in published maps and institutional affiliations.

Received: 11 February 2021 Accepted: 15 March 2021

Published online: 05 May 2021

\section{References}

1. Liu L, Oza S, Hogan D, Chu Y, Perin J, Zhu J, Lawn JE, Cousens S, Mathers C, Black RE (2016) Global, regional, and national causes of under-5 mortality in 2000-15: an updated systematic analysis with implications for the Sustainable Development Goals. Lancet 388(10063):3027-3035

2. Hospital Care for Children. Guidelines for the management of common childhood illnesses. Second Edition. In. Geneva: World Health Organization; 2013.

3. Recommendations for management of common childhood conditions: evidence for technical update of pocket book recommendations. In. Geneva: World Health Organization; 2012.

4. Mwaniki MK, Nokes DJ, Ignas J, Munywoki P, Ngama M, Newton CR, Maitland K, Berkley JA (2009) Emergency triage assessment for hypoxaemia in neonates and young children in a Kenyan hospital: an observational study. Bull World Health Organ 87(4):263-270

5. English M, Gathara D, Mwinga S, Ayieko P, Opondo C, Aluvaala J, Kihuba E, Mwaniki P, Were F, Irimu G, Wasunna A, Mogoa W, Nyamai R (2014) Adoption of recommended practices and basic technologies in a low-income setting. Arch Dis Child 99(5):452-456

6. Graham H, Bakare AA, Ayede Al, Oyewole OB, Gray A, Peel D, McPake B, Neal E, Qazi SA, Izadnegahdar R, Duke T, Falade AG (2019) Hypoxaemia in hospitalised children and neonates: a prospective cohort study in Nigerian secondary-level hospitals. EClinicalMedicine 16:51-63
7. Lazzerini M, Sonego M, Pellegrin MC (2015) Hypoxaemia as a mortality risk factor in acute lower respiratory infections in children in low and middle-income countries: systematic review and meta-analysis. PLoS One 10(9):e0136166

8. Chisti MJ, Salam MA, Smith JH, Ahmed T, Pietroni MA, Shahunja KM, Shahid AS, Faruque AS, Ashraf H, Bardhan PK, Sharifuzzaman S, Graham SM, Duke T (2015) Bubble continuous positive airway pressure for children with severe pneumonia and hypoxaemia in Bangladesh: an open, randomised controlled trial. Lancet 386(9998):1057-1065

9. McCollum ED, Mvalo T, Eckerle M, Smith AG, Kondowe D, Makonokaya D, Vaidya D, Billioux V, Chalira A, Lufesi N, Mofolo I, Hosseinipour M (2019) Bubble continuous positive airway pressure for children with high-risk conditions and severe pneumonia in Malawi: an open label, randomised, controlled trial. Lancet Respir Med 7(11):964-974

10. Dobson MB (2001) Oxygen concentrators and cylinders. Int J Tuberc Lung Dis 5(6):520-523

11. Belle J, Cohen H, Shindo N, Lim M, Velazquez-Berumen A, Ndihokubwayo JB, Cherian M (2010) Influenza preparedness in low-resource settings: a look at oxygen delivery in 12 African countries. J Infect Dev Ctries 4(7):419-424

12. Maitland K, Kiguli S, Opoka RO, Olupot-Olupot P, Engoru C, Njuguna P, Bandika V, Mpoya A, Bush A, Williams TN, Grieve R, Sadique Z, Harrison D, Rowan K (2017) Children's Oxygen Administration Strategies Trial (COAST): a randomised controlled trial of high flow versus oxygen versus control in African children with severe pneumonia. Wellcome Open Res 2:100

13. Pocket Book of Hospital Care for Children: Guidelines for the management of common childhood illnesses. In., Second edn. Geneva: World Health Organization; 2013.

14. Maitland K (2017) Different targets in children. In: 37th International Symposium on Intensive Care and Emergency Medicine Brussels.

15. Maitland K, Molyneux S, Boga M, Kiguli S, Lang T (2011) Use of deferred consent for severely ill children in a multi-centre phase III trial. Trials 12:90

16. Maitland K, Kiguli S, Opoka RO, Engoru C, Olupot-Olupot P, Akech SO, Nyeko R, Mtove G, Reyburn H, Lang T, Brent B, Evans JA, Tibenderana JK, Crawley J, Russell EC et al (2011) Mortality after fluid bolus in African children with severe infection. N Engl J Med 364(26):2483-2495

17. Abubakar A, Holding P, Van de Vijver F, Bomu G, Van Baar A (2010) Developmental monitoring using caregiver reports in a resource-limited setting: the case of Kilifi Kenya. Acta Paediatr 99(2):291-297

18. Dondorp AM, Fanello Cl, Hendriksen IC, Gomes E, Seni A, Chhaganlal KD, Bojang K, Olaosebikan R, Anunobi N, Maitland K, Kivaya E, Agbenyega T, Nguah SB, Evans J, Gesase S et al (2010) Artesunate versus quinine in the treatment of severe falciparum malaria in African children (AQUAMAT): an open-label, randomised trial. Lancet 376(9753):1647-1657

19. Pneumonia Etiology Research for Child Health Study G (2019) Causes of severe pneumonia requiring hospital admission in children without HIV infection from Africa and Asia: the PERCH multi-country case-control study. Lancet. 394(10200):757-779.

20. Common Terminology Criteria for Adverse Events (CTCAE) (2009) In. Edited by SERVICES USDOHAH, vol. Version 4. National Institutes of Health National Cancer Institute.

21. Chu DK, Kim LH, Young PJ, Zamiri N, Almenawer SA, Jaeschke R, Szczeklik W, Schunemann HJ, Neary JD, Alhazzani W (2018) Mortality and morbidity in acutely ill adults treated with liberal versus conservative oxygen therapy (IOTA): a systematic review and meta-analysis. Lancet 391(10131):1693-1705

22. Djulbegovic B (2007) Articulating and responding to uncertainties in clinical research. J Med Philos 32(2):79-98

23. Peto R, Baigent C (1998) Trials: the next 50 years Large scale randomised evidence of moderate benefits. BMJ 317(7167):1170-1171

24. Jackson RM (1985) Pulmonary oxygen toxicity. Chest 88(6):900-905

25. Perner A, Finfer S (2018) Do trials that report a neutral or negative treatment effect improve the care of critically ill patients? Yes. Intensive Care Med 44(11):1985-1988

26. Cunningham $S$, Rodriguez A, Adams T, Boyd KA, Butcher I, Enderby $B$, MacLean M, McCormick J, Paton JY, Wee F, Thomas H, Riding K, Turner SW, Williams C, Mclntosh E et al (2015) Oxygen saturation targets in infants with bronchiolitis (BIDS): a double-blind, randomised, equivalence trial. Lancet 386(9998):1041-1048 
27. Peters MJ, Jones GAL, Wiley D, Wulff J, Ramnarayan P, Ray S, Inwald D, Grocott M, Griksaitis M, Pappachan J, O’Neill L, Eaton S, Mouncey PR, Harrison DA, Rowan KM et al (2018) Conservative versus liberal oxygenation targets in critically ill children: the randomised multiple-centre pilot Oxy-PICU trial. Intensive Care Med 44(8):1240-1248

28. Martin DS, Grocott MP (2013) Oxygen therapy in critical illness: precise control of arterial oxygenation and permissive hypoxemia. Crit Care Med 41(2):423-432

29. Davis PG, Tan A, O'Donnell CP, Schulze A (2004) Resuscitation of newborn infants with 100\% oxygen or air: a systematic review and meta-analysis. Lancet 364(9442):1329-1333

30. Dauncey JW, Olupot-Olupot P, Maitland K (2019) Healthcare-provider perceptions of barriers to oxygen therapy for paediatric patients in three government-funded eastern Ugandan hospitals; a qualitative study. BMC Health Serv Res 19(1):335

31. Gilbert-Kawai ET, Mitchell K, Martin D, Carlisle J, Grocott MP (2014) Permissive hypoxaemia versus normoxaemia for mechanically ventilated critically ill patients. Cochrane Database Syst Rev 5:CD009931

32. Bradley BD, Howie SR, Chan TC, Cheng YL (2014) Estimating oxygen needs for childhood pneumonia in developing country health systems: a new model for expecting the unexpected. PLoS One 9(2):e89872

33. Djelantik IG, Gessner BD, Sutanto A, Steinhoff M, Linehan M, Moulton LH, Arjoso S (2003) Case fatality proportions and predictive factors for mortality among children hospitalized with severe pneumonia in a rural developing country setting. J Trop Pediatr 49(6):327-332

34. Nokes DJ, Ngama M, Bett A, Abwao J, Munywoki P, English M, Scott JA, Cane PA, Medley GF (2009) Incidence and severity of respiratory syncytial virus pneumonia in rural Kenyan children identified through hospital surveillance. Clin Infect Dis 49(9):1341-1349

35. Agweyu A, Lilford RJ, English M, Clinical Information Network Author $\mathrm{G}$ (2018) Appropriateness of clinical severity classification of new WHO childhood pneumonia guidance: a multi-hospital, retrospective, cohort study. Lancet Glob Health 6(1):e74-e83

36. Rochwerg B, Granton D, Wang DX, Helviz Y, Einav S, Frat JP, MekontsoDessap A, Schreiber A, Azoulay E, Mercat A, Demoule A, Lemiale V, Pesenti A, Riviello ED, Mauri T et al (2019) High flow nasal cannula compared with conventional oxygen therapy for acute hypoxemic respiratory failure: a systematic review and meta-analysis. Intensive Care Med 45(5):563-572

37. Hui DS, Chow BK, Lo T, Ng SS, Ko FW, Gin T, Chan MTV (2015) Exhaled air dispersion during noninvasive ventilation via helmets and a total facemask. Chest 147(5):1336-1343

38. Perner A, Hjortrup PB, Pettila V (2018) Focus on randomised clinical trials. Intensive Care Med 44(12):2257-2259 